\title{
The use of experimental design methodology in the formulation of a new additive for the dispersion of elemental sulfur in triple superphosphate fertilizer
}

\author{
Asmae El Agri ${ }^{1, *}$, Anass Hafnaoui ${ }^{2}$, Mehdi Khouloud ${ }^{3}$, Mohammed Senhaji Lakehal ${ }^{1}$, \\ Mohammed El Asri ${ }^{1,3}$ and Abdeslem Meliani ${ }^{1}$ \\ ${ }^{1}$ Laboratory of Applied Organic Chemistry, FST FEZ USMBA Road Imouzzer, PO Box 2202, Fez, Morocco \\ ${ }^{2}$ Innovation, Fertilizers department, OCP Group S.A, Jorf lasfar, Morocco \\ ${ }^{3}$ Chemical \& Biochemical Sciences Laboratory, Mohammed VI Polytechnic University, Lot 660, \\ Hay Moulay Rachid, 43150, Ben Guerir, Morocco
}

\begin{abstract}
Yields improvement of the crop depends on many parameters witch each of them acts for a specific manner to boost the plant growth and allow the soil to be more efficient to any kind of plant. Our research is based on the implementation of elemental sulfur into the preparation of triple superphosphate fertilizer and its dispersion into the blend. By adding a small amount of it to the mixture, sulfur particles disperse uniformly by using additives in the phosphate fertilizer.

This technique is successfully reached by integrating many additives obtained from different chemical industries to spread out the sulfur particle in the fertilizer.

Several experiments were done by adopting the experimental design methodology (DOE) related to a screening mixture design to select the best surfactant used. So, nine commercial products with different chemical proprieties have been evaluated as a dispersant of elemental sulfur in triple superphosphate fertilizer. First, thanks to the screening mixture design, three products have been chosen for this formulation. Second, by using the mixture design method, new dispersants of elemental sulfur in triple superphosphate fertilizer have been reached. With this method, apart from it is being possible to obtain several dispersants, it is also possible to control the distribution and the average of the particle diameter of the elemental sulfur. Moreover, statistical validation tests confirm the achievement of the sulfur particle size of approximately $1000 \mu \mathrm{m}$.
\end{abstract}

Keywords: Elemental sulfur; Surfactant; Design of experiment; Mixture design; Screening mixture design; Phosphate fertilizer.

\section{Introduction}

Sulfur is a vital nutrient for plant growth. The most common sulfur sources contain either sulphates $\left(\mathrm{SO}_{4}{ }^{2-}\right.$ ) or elemental sulfur $\left(\mathrm{S}_{8}\right)$. Sulphates components are found mainly in the composition of the conventional fertilizers that include gypsum (14-18\% S), ammonium sulphate $(24 \% \mathrm{~S})$, and single super phosphate $(12 \% \mathrm{~S})^{1,2}$. The sulphates even though their sulfur is readily available for plant uptake, their low S content, and their natural leaching into the soil significantly reduce their use and foster elemental sulfur demand. In contrast, elemental sulfur does not leach into the soil as quickly as sulphates because the sulfur is oxidized to sulphates.

Many environmental factors are influencing elemental sulfur oxidation in the soil and affecting its oxidation rates such as temperature, moisture,

*Corresponding author: Asmae El Agri

Email address: elagriasmae@yahoo.fr

DOI: http://dx.doi.org/10.13171/mjc10602006271453aea aeration, $\mathrm{pH}$, microbial diversity, sulfur particle size, dispersion in the soil and the fertilizer

formulation $^{3-7}$.

The Previous works ${ }^{3,6,8,9}$, show clearly the larger contact area of elemental sulfur occupied, the more comfortable, it will be oxidized and subsequently more efficient. So, the oxidation rate is inversely proportional to the elemental sulfur particle size. Despite that, more the size of its particles is smaller more its handling in factories and in fields is very hazardous due to their high flammability.

This work is focused on the preparation of a triple superphosphate fertilizer (TSP),_doped with a small particle of elemental sulfur with a size of $1000 \mu \mathrm{m}$. It should be noted that TSP is prepared with phosphoric acid, which is very hydrophilic, while elemental sulfur is very hydrophobic. During fertilizer preparation, sulfur particles aggregate, resulting in a

Received April 22, 2020

Accepted May 16, 2020

Published June 27, 2020 
heterogeneous dispersion of coarse particles in the fertilizer ${ }^{10}$. Accordingly, the big challenge for the application of elemental sulfur as a nutrient in the phosphate fertilizer is associated with its natural tendency to aggregate, resulting in the loss of its beneficial properties. To overcome this problem, it is commonly used several surfactants to foster its dispersion. The surfactant compounds have an amphiphilic structure containing a hydrophilic head and a lipophilic tail, are appropriately used as a dispersant agent. This kind of product proves dispersion efficiency by decreasing the surface tension of water ${ }^{11}$ and by adsorbing it on the surface of elemental sulfur through hydrophobic interactions ${ }^{12}$. Surfactant molecules adsorbed on the surface maintain stable the colloid through the electrostatic repulsion between the electric charges of their functional groups ${ }^{13}$, and their dispersing efficiency depends on the tail and the head of the surfactant used.

Surfactants or surface-active agents are used in many products manufacturing. Several industries, such as pharmaceutics, cosmetics, agri-food, textile, plastics, painting, and coating, use them in their products. It is noted that, depending on their application, these surfactants could be used as emulsifiers, wetting agents, dispersants, coupling agents, flocculants, coagulants, etc. Generally, surfactants are classified into four categories depending on the hydrophilic part (head): anionic, cationic, nonionic, and amphoteric. In this case, several authors, ${ }^{14-20}$, describe the surface properties of each type of additives and their application. In addition, previous work brought up various methods, and several surfactants have been used for the dispersion of elemental sulfur in fertilizers ${ }^{21-25}$.

Considering the large number of surfactants that can scatter elemental sulfur in phosphate fertilizers, we have picked up nine of them. Foremost, we wanted to determine the effect of each product on sulfur dispersion. According to the OFAT method (one factor at a time), it would be much more difficult to find out the effect of nine products because of the large number of experiments required. So, we choose the screening mixture design for this study. Then, from its nine products, we select three of them, which we formulated new reagents using mixture design.

According to the bibliography, Cornell ${ }^{26}$ defined the mixture design as an experiment structure whose response is assumed to depend exclusively on the relative proportions of the components in the mixture and not the quantity of the mixture. As well, the modification of the responses depends on the relative proportions of constituents in the mixture. Furthermore, the simplex design for mixtures, is well known by the work of Scheffe ${ }^{27}$ in 1963 . According to several scientists ${ }^{28-33}$, mixture design is generally used to examine the formulations that are composed of many constituents to determine the best combination of all the components.
When each project begins, especially when there is not sufficient information available, several variables are potentially active. In this case, the screening design is highly recommended.

Screening design for ordinary independent variables ${ }^{34-36}$ is used as the first step in an industrial process to study the influence of many parameters. The same method applies to screen the mixture components. However, there is a difference between these two cases, because of the constraints that apply to the components of the mixture ${ }^{37-39}$. Other works ${ }^{40,41}$ reports the use of screening mixture design for the mix issue, particularly when the number of constituents exceeds six. As a consequence, the experimental design of the mixture has proved to be a useful approach being explored in many fields and has demonstrated a good result because the experimental design is based on mathematical tools used to model and predict the response.

In this work, we have used surfactant additives to disperse elemental sulfur $\mathrm{S}^{0}$ in triple superphosphate (TSP) fertilizer. For this purpose, we have:

1- Evaluated the dispersing power of elemental sulfur using some commercial additives. For this evaluation, we have used a screening design methodology for the mixture to organize our experiments.

2- Proposed a new formulation based on three commercial additives for elemental sulfur dispersion. For this formulation, we have used a mixture design methodology.

\section{Experimental}

2.1. Manufacture of triple superphosphate fertilizer enriched with elemental sulfur.

Triple superphosphate fertilizer (TSP) is generally prepared by the attack of phosphoric acid (42\% of $\mathrm{P}_{2} \mathrm{O}_{5}$ ) on phosphate rock ${ }^{42-44}$. However, we focus in this study to manufacture the phosphate fertilizer enriched with elemental sulfur (TSP-S). For this preparation, an amount equivalent to $0,5 \%$ of surfactant additive is first added to the phosphoric acid, which is heated to $65^{\circ} \mathrm{C}$ and then, the molten sulfur is added. Next, the micronized phosphate rock is added to the elemental sulfur and phosphoric acid. The blend is mixed for $20 \mathrm{~min}$.

Many fertilizer specialists ${ }^{45-50}$ have recommended adding a surfactant for the best dispersion of elemental sulfur in fertilizer. Some preliminary tests have shown that the addition of $0,5 \%$ of surfactant significantly improves the dispersion of elemental sulfur in TSP fertilizer.

As already mentioned, we are interested in this work to surfactant additives, which can disperse elemental sulfur in TSP fertilizer. The parameter adjustment of the process of manufacturing TSP fertilizer enriched with elemental sulfur (TSP-S) has been fixed, as indicated in Table 1. 
Furthermore, the sulfur used in this work is in molten form, as the use of sulfur in powder form has many drawbacks:

- Risk of explosion due to any form of handling;

Table 1. Setting parameters for the preparation of TSP-S fertilizer.

\begin{tabular}{|c|c|}
\hline Parameter & Adjustment \\
\hline Temperature of phosphoric acid & $65^{\circ} \mathrm{C}$ \\
\hline Stirring time & $20 \mathrm{~min}$ \\
\hline Stirring speed & $300 \mathrm{tr} / \mathrm{min}$ \\
\hline Amount of surfactant additive & $0,5 \%$ \\
\hline The title of $\mathbf{P}_{\mathbf{2}} \mathbf{O}_{\mathbf{5}}$ & $42 \%$ \\
\hline Temperature of the mixture & $65^{\circ} \mathrm{C}$ \\
\hline Sulfur content & $10 \%$ \\
\hline Sulfur incorporation manner & Melted \\
\hline
\end{tabular}

2.2. Surfactants additives for elemental sulfur dispersion

For efficient use, elemental sulfur must be constitute of the finest particles (less than $250 \mu \mathrm{m}$ ) and homogeneously dispersed in fertilizers ${ }^{10,51,52}$.
- The energetic character of the micronization process;

- The dust generation.

In this study, we propose to identify through a screening mixture design, the effect of nine products on the size of elemental sulfur particles into TSP fertilizer. These additives are all differentiated by the chemical nature of the polar head. The following Table 2 shows perfectly more details and the use of these additives.

Table 2. The additives used for elemental sulfur dispersion in TSP fertilizer.

\begin{tabular}{|c|c|c|c|}
\hline Additive & Type of additive & Chemical function & Suppliers \\
\hline Marasperse CBoS-4 & Anionic & Sodium Lignosulfonate & LignoTech USA \\
\hline Borrosperse & Anionic & Sodium Lignosulfonate & Borregard lignotech \\
\hline Morwet D-425 & Anionic & Alkyl Naphtalène Sulfonate & $\begin{array}{c}\text { AkzoNobel Surface } \\
\text { Chemistry }\end{array}$ \\
\hline Ethomeen T/25 & Nonionic & Tallow Amine Ethoxylate & $\begin{array}{c}\text { AkzoNobel Surface } \\
\text { Chemistry }\end{array}$ \\
\hline Biosoft N1-5 & Nonionic & Alcohol Ethoxylates & Stepan Company \\
\hline Triton TM X-165 & Nonionic & Octylphenol Ethoxylates & Dow Chemical \\
\hline Toximul TA5 & Cationic & $\begin{array}{c}\text { Amine Ethoxylates } \\
\text { Polyacrylamide (High } \\
\text { molecular weight) }\end{array}$ & Stepan Company \\
\hline Zetag 8180 & Cationic & $\begin{array}{c}\text { Polyacrylamide } \text { (Low } \\
\text { molecular weight) }\end{array}$ & BASF \\
\hline
\end{tabular}

As mentioned previously, the response measured in this work is the size of elemental sulfur particles in the TSP fertilizer. For this measurement, we used a stereo-microscope device (produced from Euromex binoculars).

\section{Results and Discussion}

3.1. Evaluation of the effect of some additives in elemental sulfur dispersion

Once TSP fertilizer enriched with elemental sulfur prepared, a stereomicroscope analysis allows determining the particle sizes of elemental sulfur. Fig. 1 shows the aspect of elemental sulfur particles for two samples with (A) and without (B) the use of surfactant additives. 


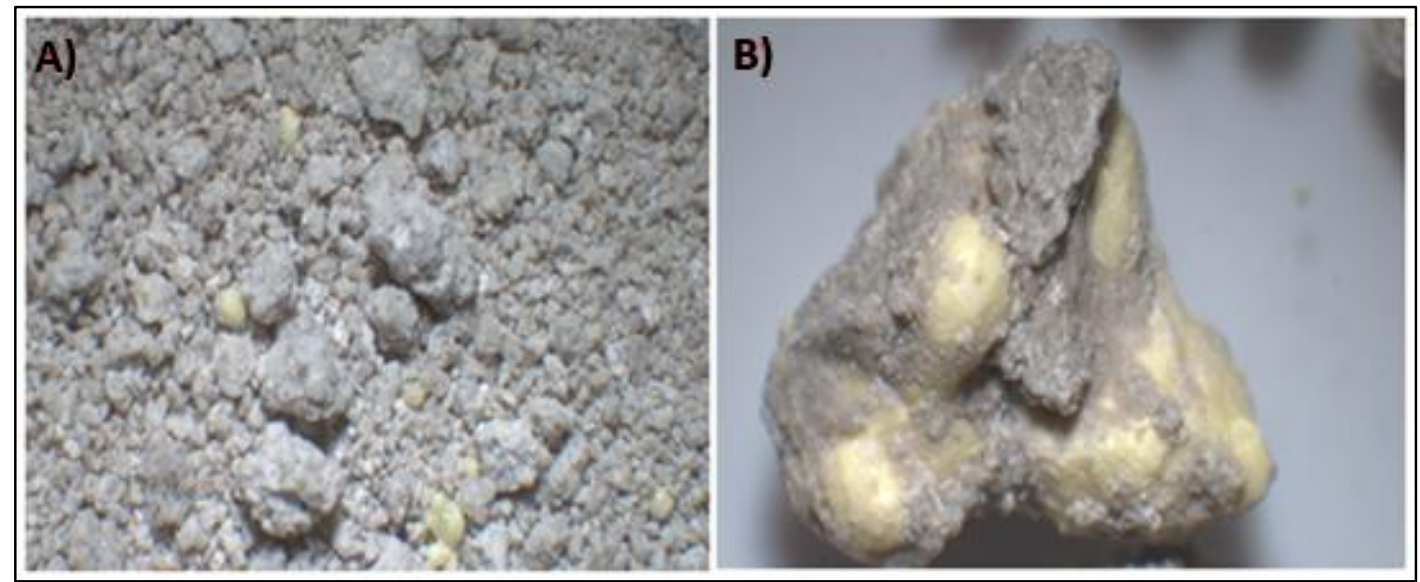

Figure 1. Stereo-microscope imagery of elemental sulfur particles - A) trial number 17: with surfactant; B) without surfactant use

The screening mixture design is used to determine the effect of nine components that are depending on the shape of the experimental region. There are two ways to plan the experiments in the simplex:

1- The first contains $2 q+1$ points is suggested for simplex using the pseudo-components.

2- The second contains $3 q+1$ points, and this one is the most advisable.
Experimental points are sited along the component axes, represented by $\mathrm{X}_{1}, \mathrm{X}_{2}$, and $\mathrm{X}_{3}$ axis, that are illustrated a simplex of them in the following figure (Fig.2). These experimental points can be organized into four classes A, B, C, and D explaining in the following table (Table 3 ), which are conducting to build the screening mixture design.

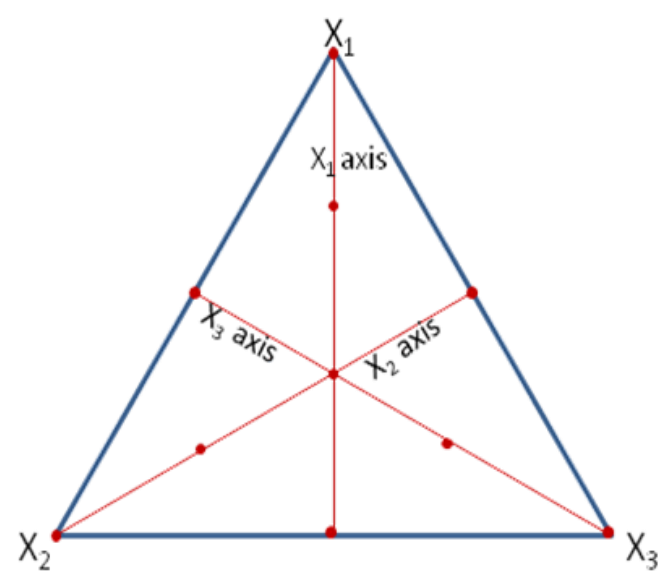

Figure 2. Simplex design for three components

Table 3. Composition points of a mixture screening design.

\begin{tabular}{|c|c|c|c|}
\hline Code & Name & Number & Composition \\
\hline A & Vertices & $q$ & $x_{i}=1, x j=0$, all $j \neq i$ \\
\hline B & Interior & $q$ & $x_{i}=(q+1) / 2 q$ \\
$x_{j}=(2 q)^{-1}$ all $j \neq i$
\end{tabular}

In this work, we are interested in evaluating the effect of nine components on the particle size of elemental sulfur into the TSP fertilizer. Table 4 illustrates the screening mixture design with the analysis of the response (Fig.3) that are indicating the form of the particle sizes of elemental sulfur, showing an average of $676 \mu \mathrm{m}$. Moreover, a large part of the particle sizes is around $700 \mu \mathrm{m}$. 
Table 4. Screening experimental design for mixture.

\begin{tabular}{|c|c|c|c|c|c|c|c|c|c|c|}
\hline 寻 & 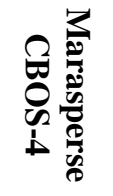 & $\begin{array}{l}\square \\
0 \\
0 \\
8 \\
8 \\
0 \\
0 \\
0 \\
0\end{array}$ & 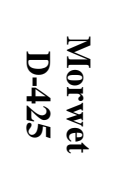 & 忿兽 & Z & 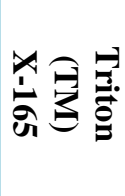 & 忿总 & 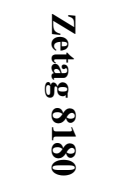 & 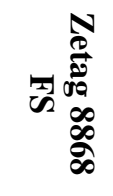 & $\stackrel{\prec}{E}$ \\
\hline 1 & 0 & 0.1250 & 0.1250 & 0.1250 & 0.1250 & 0.1250 & 0.1250 & 0.1250 & 0.1250 & 617.96 \\
\hline 2 & 0.5556 & 0.0556 & 0.0556 & 0.0556 & 0.0556 & 0.0556 & 0.0556 & 0.0556 & 0.0556 & 639.52 \\
\hline 3 & 1.0000 & 0 & 0 & 0 & 0 & 0 & 0 & 0 & 0 & 1101.80 \\
\hline 4 & 0.1250 & 0 & 0.1250 & 0.1250 & 0.1250 & 0.1250 & 0.1250 & 0.1250 & 0.1250 & 511.98 \\
\hline 5 & 0.0556 & 0.5556 & 0.0556 & 0.0556 & 0.0556 & 0.0556 & 0.0556 & 0.0556 & 0.0556 & 418.60 \\
\hline 6 & 0 & 1.0000 & 0 & 0 & 0 & 0 & 0 & 0 & 0 & 707.98 \\
\hline 7 & 0.1250 & 0.1250 & 0 & 0.1250 & 0.1250 & 0.1250 & 0.1250 & 0.1250 & 0.1250 & 600.32 \\
\hline 8 & 0.0556 & 0.0556 & 0.5556 & 0.0556 & 0.0556 & 0.0556 & 0.0556 & 0.0556 & 0.0556 & 572.18 \\
\hline 9 & 0 & 0 & 1.0000 & 0 & 0 & 0 & 0 & 0 & 0 & 617.54 \\
\hline 10 & 0.1250 & 0.1250 & 0.1250 & 0 & 0.1250 & 0.1250 & 0.1250 & 0.1250 & 0.1250 & 479.64 \\
\hline 11 & 0.0556 & 0.0556 & 0.0556 & 0.5556 & 0.0556 & 0.0556 & 0.0556 & 0.0556 & 0.0556 & 615.16 \\
\hline 12 & 0 & 0 & 0 & 1.0000 & 0 & 0 & 0 & 0 & 0 & 1089.34 \\
\hline 13 & 0.1250 & 0.1250 & 0.1250 & 0.1250 & 0 & 0.1250 & 0.1250 & 0.1250 & 0.1250 & 575.12 \\
\hline 14 & 0.0556 & 0.0556 & 0.0556 & 0.0556 & 0.5556 & 0.0556 & 0.0556 & 0.0556 & 0.0556 & 517.30 \\
\hline 15 & 0 & 0 & 0 & 0 & 1.0000 & 0 & 0 & 0 & 0 & 678.44 \\
\hline 16 & 0.1250 & 0.1250 & 0.1250 & 0.1250 & 0.1250 & 0 & 0.1250 & 0.1250 & 0.1250 & 543.06 \\
\hline 17 & 0.0556 & 0.0556 & 0.0556 & 0.0556 & 0.0556 & 0.5556 & 0.0556 & 0.0556 & 0.0556 & 568.96 \\
\hline 18 & 0 & 0 & 0 & 0 & 0 & 1.0000 & 0 & 0 & 0 & 898.80 \\
\hline 19 & 0.1250 & 0.1250 & 0.1250 & 0.1250 & 0.1250 & 0.1250 & 0 & 0.1250 & 0.1250 & 702.66 \\
\hline 20 & 0.0556 & 0.0556 & 0.0556 & 0.0556 & 0.0556 & 0.0556 & 0.5556 & 0.0556 & 0.0556 & 546.98 \\
\hline 21 & 0 & 0 & 0 & 0 & 0 & 0 & 1.0000 & 0 & 0 & 828.52 \\
\hline 22 & 0.1250 & 0.1250 & 0.1250 & 0.1250 & 0.1250 & 0.1250 & 0.1250 & 0 & 0.1250 & 540.96 \\
\hline 23 & 0.0556 & 0.0556 & 0.0556 & 0.0556 & 0.0556 & 0.0556 & 0.0556 & 0.5556 & 0.0556 & 544.32 \\
\hline 24 & 0 & 0 & 0 & 0 & 0 & 0 & 0 & 1.0000 & 0 & 1053.78 \\
\hline 25 & 0.1250 & 0.1250 & 0.1250 & 0.1250 & 0.1250 & 0.1250 & 0.1250 & 0.1250 & 0 & 445.06 \\
\hline 26 & 0.0556 & 0.0556 & 0.0556 & 0.0556 & 0.0556 & 0.0556 & 0.0556 & 0.0556 & 0.5556 & 504.98 \\
\hline 27 & 0 & 0 & 0 & 0 & 0 & 0 & 0 & 0 & 1.0000 & 1512.70 \\
\hline 28 & 0.1111 & 0.1111 & 0.1111 & 0.1111 & 0.1111 & 0.1111 & 0.1111 & 0.1111 & 0.1111 & 491.54 \\
\hline
\end{tabular}




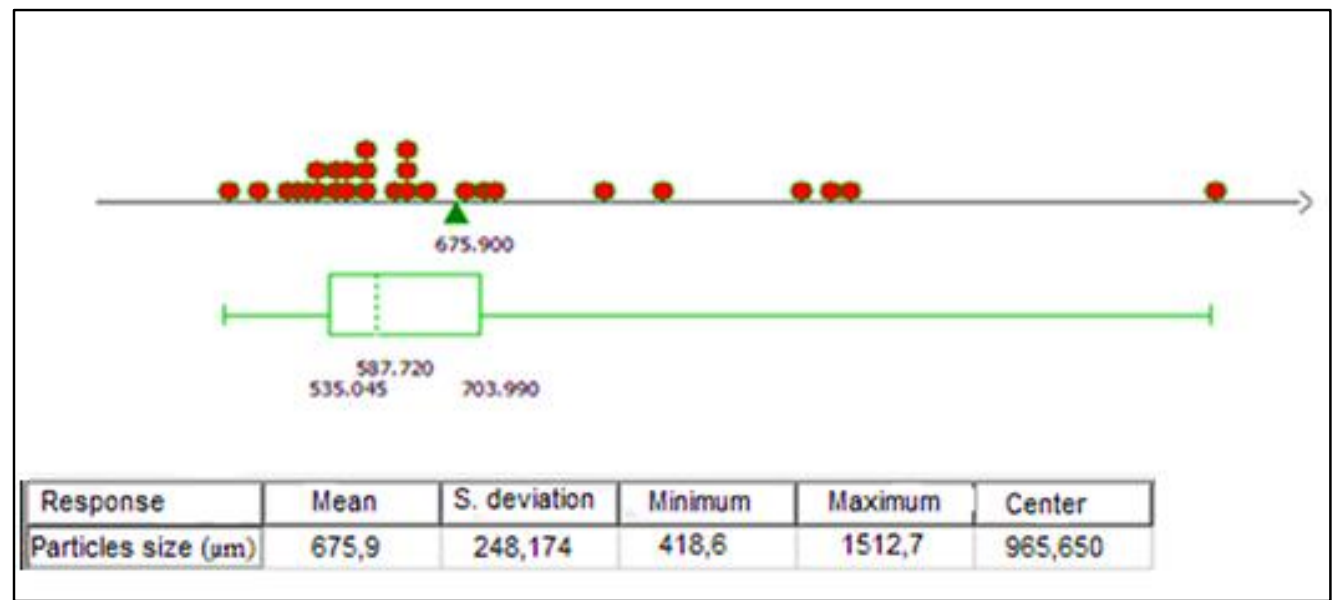

Figure 3. Box plot construction of elemental sulfur distribution

The data obtained from the simplex screening design can be analyzed graphically by plotting the response along each component axis. Fig. 4 shows the resulting plot for the nine components. A study of the previous figure gives away clearly several conclusions:

- Component 9 (Zetag 8868 FS) has a very significant positive effect. The size of the elemental sulfur particles increases with the amount of component 9 .

- Component 1, 4, and 8 (Marasperse CBOS-4, Ethomeen T/25, and Zetag 8180) have the same significant and positive effects.

- Component 6 and 7 (Triton (TM) X-165 and Toximul TA5) (Component 7) show the same middle effects.
- Component 2, 3, and 5 (Borresperse, Morwet D425, and Biosoft N1-5) have the very smallest effects.

According to the results mentioned above, the nine products have different effects on the response. Some are rapidly increasing the particle size of elemental sulfur; others have a moderate impact while some are reducing it.

In this work, we aim to develop an additive used to prepare the phosphate fertilizer enriched with the elemental sulfur particle size of about $1000 \mu \mathrm{m}$. To do this, we chose three of the nine components. Each one is being taken in one of the groups classified according to their effects (very significant, high, and middle effect) previously mentioned: Components 6 , 8, and 9 (Triton X-165, Zetag 8180 and Zetag 8868FS).

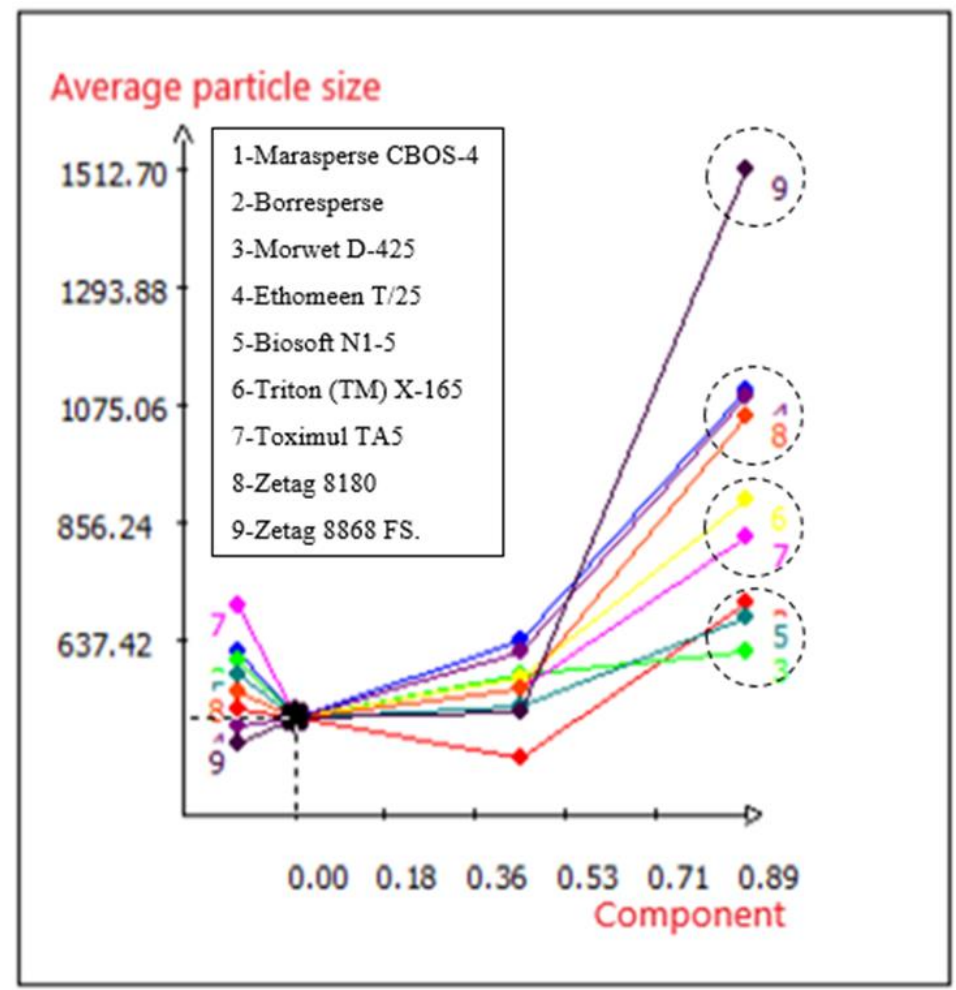

Figure 4. Plot of response along each component axis 
When working with three components, the experimental domain corresponds to an equilateral triangle. A point in the triangle area can univocally identify all the possible mixtures with the vertices corresponding to the pure components. In our case, it was clear that the region of interest was only a small part of the equilateral.

Indeed, as we can see clearly in Fig.4 above, with a high content of these three compounds, the particle sizes of the sulfur increases, to examine the influence of the three components on the consistency of the formulation carefully and to set the limits of a useful interval of their concentrations in terms of effectiveness, a mixture experimental design with constraints was planned. According to the work of Bezerra and all ${ }^{53}$, constraints can set lower and upper limits for the variables. These limits establish a new experimental domain that constitutes a fraction of the complete domain. Also, these constraints enable an efficient and practical study without falling into impossible experimental situations.

For this study, we set upper limits to the three components. These proportions could be written as:

$$
\begin{array}{ll}
\sum_{i=1}^{3} X i=1 \rightarrow & 0 \leq \mathrm{X} 1 \leq 0.5 \\
& 0 \leq \mathrm{X} 2 \leq 0.5 \\
& 0 \leq \mathrm{X} 3 \leq 0.5
\end{array}
$$

\subsection{A new Formulation for elemental sulfur dispersion}

According to the work of Scheffe ${ }^{27}$, the special cubic form is :

$\mathrm{Y}=\sum_{1 \leq \mathrm{i} \leq n} \mathrm{a}_{\mathrm{i}} \mathrm{X}_{\mathrm{i}}+\sum_{1 \leq \mathrm{i}<j \leq n} \mathrm{a}_{\mathrm{ij}} \mathrm{X}_{\mathrm{i}} \mathrm{X}_{\mathrm{j}}+\sum_{1 \leq \mathrm{i}<j<k \leq n} \mathrm{a}_{\mathrm{ijk}} \mathrm{X}_{\mathrm{i}} \mathrm{X}_{\mathrm{j}} \mathrm{X}_{\mathrm{k}}$

For three components, this model becomes:

$\mathrm{Y}=\mathrm{a}_{1} \mathrm{X}_{1}+\mathrm{a}_{2} \mathrm{X}_{2}+\mathrm{a}_{3} \mathrm{X}_{3}+\mathrm{a}_{12} \mathrm{X}_{1} \mathrm{X}_{2}+\mathrm{a}_{13} \mathrm{X}_{1} \mathrm{X}_{2}$

$$
+a_{23} X_{2} X_{3}+a_{123} X_{1} X_{2} X_{3}
$$

For the special cubic model and when we have three components, at least ten experiences must be carried out. For more efficiency, we have chosen fourteen experiences. As mentioned previously, the measured response is the particle sizes of elemental sulfur in the slurry of TSP fertilizer. Table 5, groups the data of the mixture experimental design and response.

Table 5. Mixture experimental design of $S^{0}$ dispersion in TSP fertilizer.

\begin{tabular}{|c|c|c|c|c|}
\hline Trial number & Triton X-165 & Zetag 8180 & Zetag 8868 FS & Y $(\boldsymbol{\mu m})$ \\
\hline $\mathbf{1}$ & 0 & 0.5000 & 0.5000 & 1139.04 \\
\hline $\mathbf{2}$ & 0.5000 & 0 & 0.5000 & 1161.02 \\
\hline $\mathbf{3}$ & 0.5000 & 0 & 0.5000 & 1282.68 \\
\hline $\mathbf{4}$ & 0.5000 & 0 & 0.5000 & 1153.18 \\
\hline $\mathbf{5}$ & 0.5000 & 0.5000 & 0 & 746.06 \\
\hline $\mathbf{6}$ & 0.5000 & 0.5000 & 0 & 797.72 \\
\hline $\mathbf{7}$ & 0.2500 & 0.2500 & 0.5000 & 944.58 \\
\hline $\mathbf{8}$ & 0.2500 & 0.5000 & 0.2500 & 961.90 \\
\hline $\mathbf{9}$ & 0.5000 & 0.2500 & 0.2500 & 1005.76 \\
\hline $\mathbf{1 0}$ & 0.3333 & 0.3333 & 0.3333 & 1102.78 \\
\hline $\mathbf{1 1}$ & 0.3333 & 0.3333 & 0.3333 & 1083.04 \\
\hline $\mathbf{1 2}$ & 0.1667 & 0.4167 & 0.4167 & 997.64 \\
\hline $\mathbf{1 3}$ & 0.4167 & 0.1667 & 0.4167 & 969.22 \\
\hline
\end{tabular}

After the data treatment of this design and thanks to the statistical distribution of elemental sulfur in TSP fertilizer shown in Fig.5, we can unambiguously conclude that our aim is mostly achieved. Because the average of the particle sizes is $1024 \mu \mathrm{m}$ and the majority of it is around this value. Moreover, as mentioned previously, the target particle size was around $1000 \mu \mathrm{m}$. 


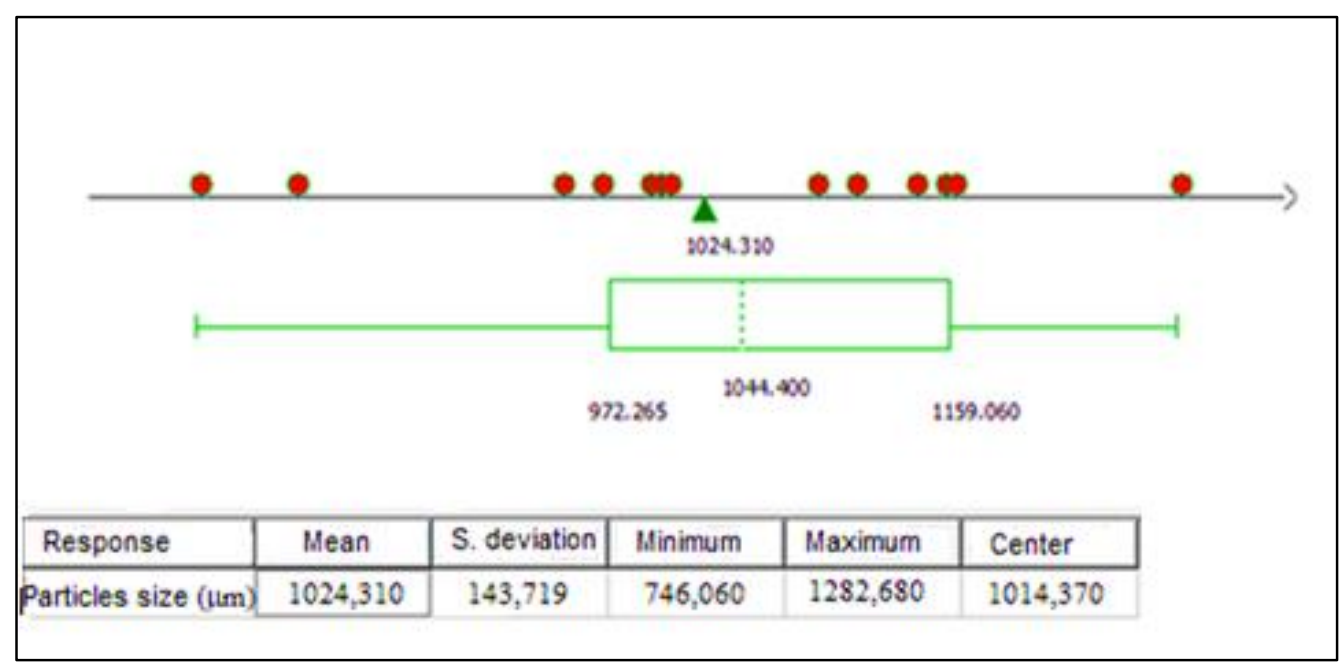

Figure 5. Box plot construction of the new formulation

A special cubic model to suit these experimental data, can be expressed as follows according to the original components:

$Y=510.93 X_{1}+1033.77 X_{2}-496.39 X_{3}+4738.87$ $X_{1} X_{3}+3508.27 X_{2} X_{3}-6711.34 X_{1} X_{2} X_{3}$

With $\mathrm{X}_{1}, \mathrm{X}_{2}$ and $\mathrm{X}_{3}$ are the three components: Triton $\mathrm{X}-165$, Zetag 8180, and Zetag 8868 FS, respectively. $\mathrm{X}_{1} \mathrm{X}_{2}, \quad \mathrm{X}_{1} \mathrm{X}_{3}, \quad \mathrm{X}_{2} \mathrm{X}_{3}$, and $\mathrm{X}_{1} \mathrm{X}_{2} \mathrm{X}_{3}$ describe the interactions between all the_components.
Before using the model for all predictions, it is necessary to validate it statistically according to the following approach:

1- Analysis of variance (ANOVA) is one of the most important statistical validation tests ${ }^{54}$. The ANOVA for the response led to the results shown in Table 6 . The special cubic model selected for the response is very significant $(\mathrm{p}$-value $=0.09<5$ ). The lack-of-fit test (Table 6) indicated that the postulated model would describe the particle sizes of elemental sulfur in the phosphate fertilizer adequately (p-value $64>5$ ).

Table 6. ANOVA table of the mixture design.

\begin{tabular}{|c|c|c|c|c|c|}
\hline Item & Sum of squares & Degrees of freedom & Mean square & F statistic & P-value \\
\hline Model & 240629.00 & 5 & 48125.90 & 13.80 & $0.09 * * *$ \\
\hline Residual error & 27889.00 & 8 & 3486.12 & & \\
\hline Validity & 11303.00 & 4 & 2825.97 & 0.68 & 64.0 \\
\hline Error & 16585.10 & 4 & 4146.28 & & \\
\hline Total & 268518.00 & 13 & & \\
\hline
\end{tabular}

2- The determination coefficient of the model $\left(\mathrm{R}^{2}=\right.$ 0.92) shows a good correlation between the independent variables, suggesting that the fitted model could explain $92 \%$ of the total variation. Because the value of this coefficient is closer to 1 , that it is mean that the model is more adapted to the measured responses ${ }^{55}$.
3- Fig.6 illustrates a satisfactory typical probability plot of residuals. Indeed, the normal distribution of the residuals shows that the mathematical model is well fitted $^{56}$. 


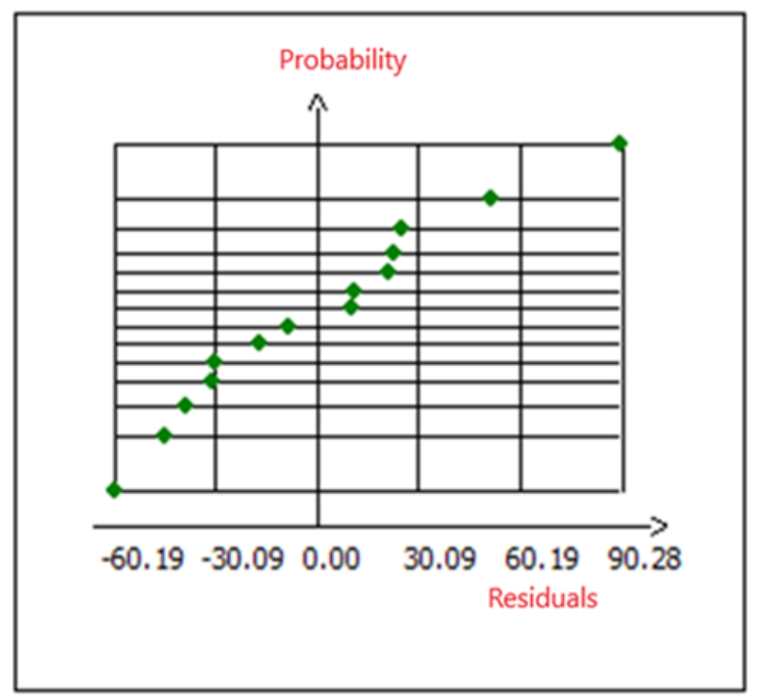

Figure 6. Normal probability plot of the new formulation

In conclusion, we can conclude that the special cubic model describes the response surface adequately and allows us to use it as a prediction equation. We may also conclude that this model gives an adequate description of the response of interest within the region of these data.

Once the model is validated, it can be used for calculating the response value at any point in the experimental domain of interest. After that, we want particle sizes of elemental sulfur in phosphate fertilizers ranging from 950 to $1100 \mu \mathrm{m}$

We used the model to have two graphs: response trace (Fig.7) and contour plot (Fig.8a et Fig.8b). Due to the correlation between all the components, the effect of each element of the response is complicated to obtain it. The response trace plot can be used to see how the response changes when each component changes from its reference point, which is generally the main objective ${ }^{26}$. In our case, from the response trace plot (Fig.7), it can be noticed that:

- The Triton X-165 and Zetag 8180 have both a similar behavior. Their effect is classified as a negative one. The particle sizes of both components start from a high value and decrease progressively as their quantity increases.

- An opposite effect can be observed with the Zetag 8868FS. Since the green curve for the third component changes significantly, this means when the Zetag 8868FS's amount varies along Cox's direction, and other components keep the same ratio, the particles size changes too. Fig.7 shows also when the amount of the Zetag 8868FS increases to $33.33 \%$ (centroid of the simplex) the particle sizes increases too. At this point, the response reaches its maximum. At a higher amount, an increase of the Zetag 8868FS percentage leads to a remarkable particle sizes decrease.

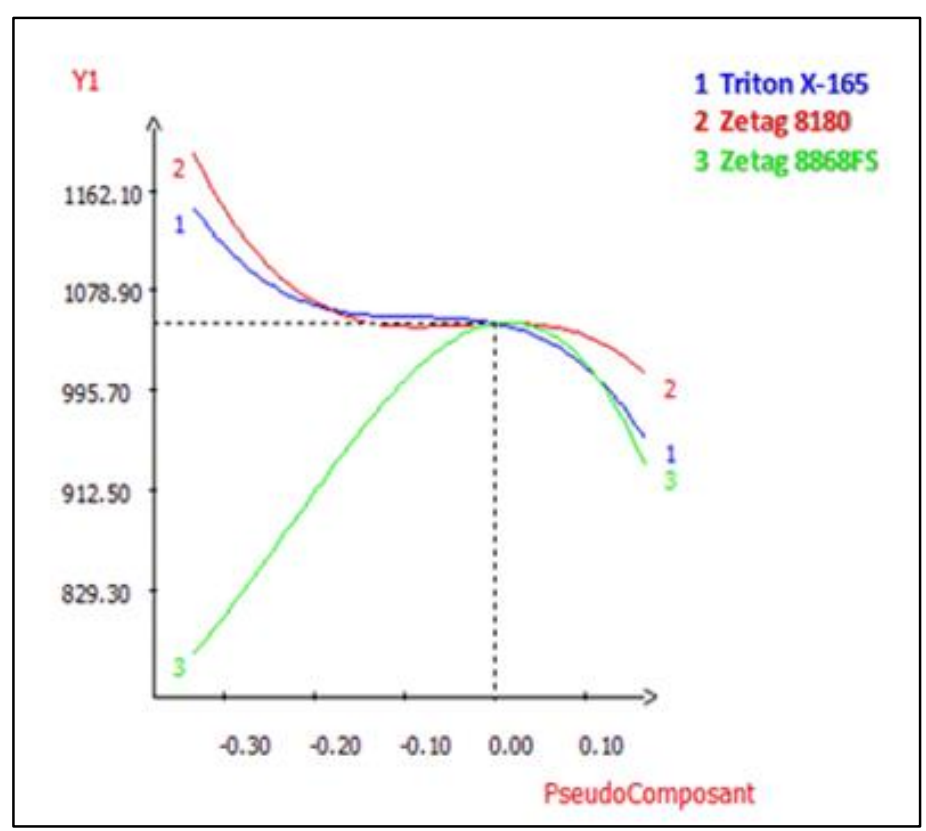

Figure 7. Response trace plot for the particle size of elemental sulfur in TSP fertilizer 
Fig. 8 (a) and (b) are respectively the 3D surface plot and the $2 \mathrm{D}$ contour plot. Both of them were generated to find the surface of the optimal response mixtures.

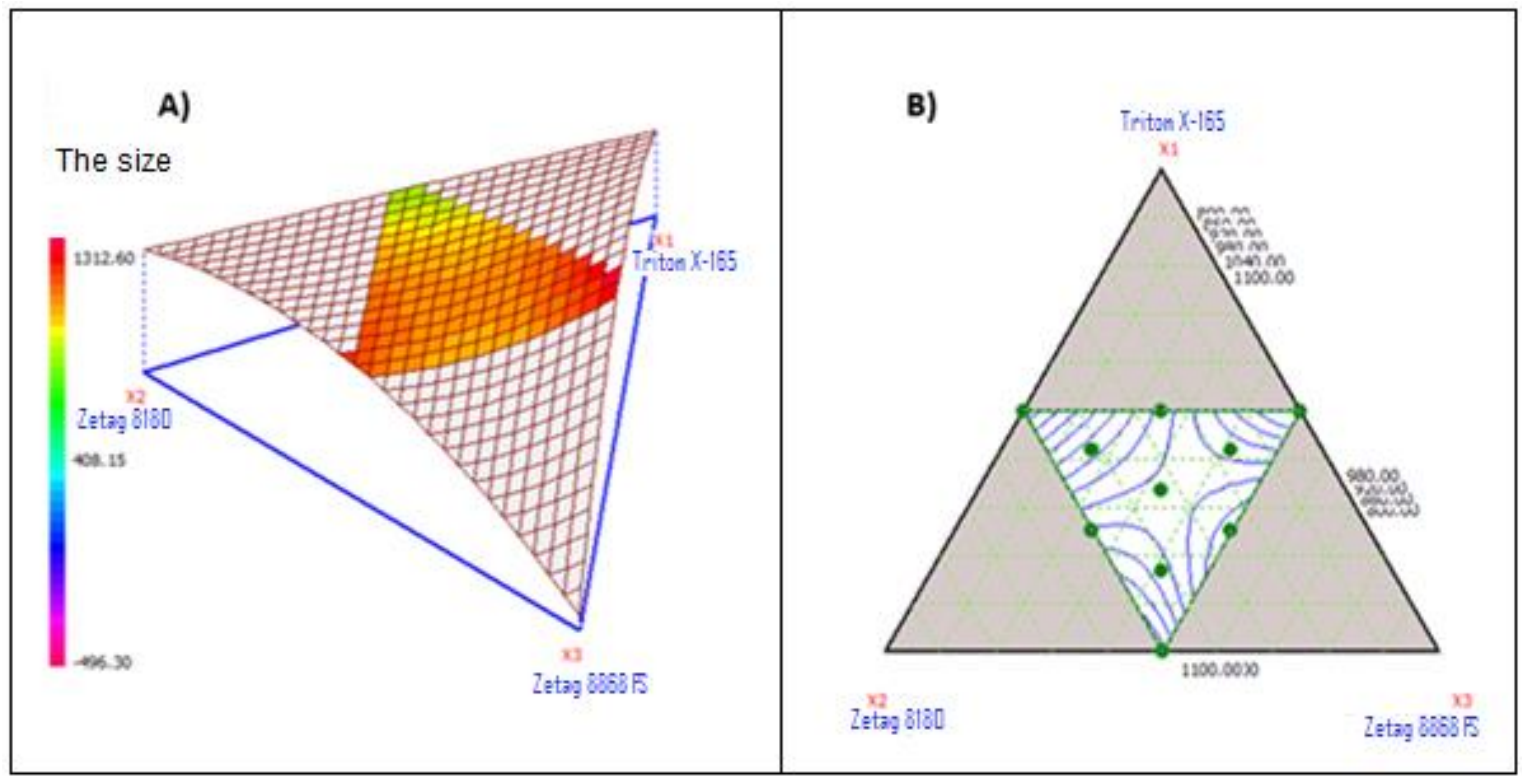

Figure 8. Contour plot 3D (a) and 2D (b) for the particles size of elemental sulfur in TSP fertilizer

It must underline that the surface plot (Fig.8a) provides a three-dimensional view that may give a clear picture of the response surface. The color palette allows us to split the response surface according to the value of the particle sizes. Furthermore, the contour plot provides a two-dimensional view where all points that have the same response are connected to produce contour lines of constant responses (Fig.8b).

Fig.9 shows the overlaid contour plot of particle sizes (white area), identifying the area of the mixture that defining the range of the particle sizes from 950 to $1100 \mu \mathrm{m}$. The red section of the same figure represents the response surface prohibited.

Experiments were carried out under optimal operating conditions (white area of the Fig.9) generated by NemrodW software ${ }^{57}$ to validate the model. The test, as formulated (40\% Triton X-165, 40\% Zetag 8180 and $20 \%$ Zetag 8868 FS), was repeated three times. For each experiment, we determine the size of elemental sulfur particles.

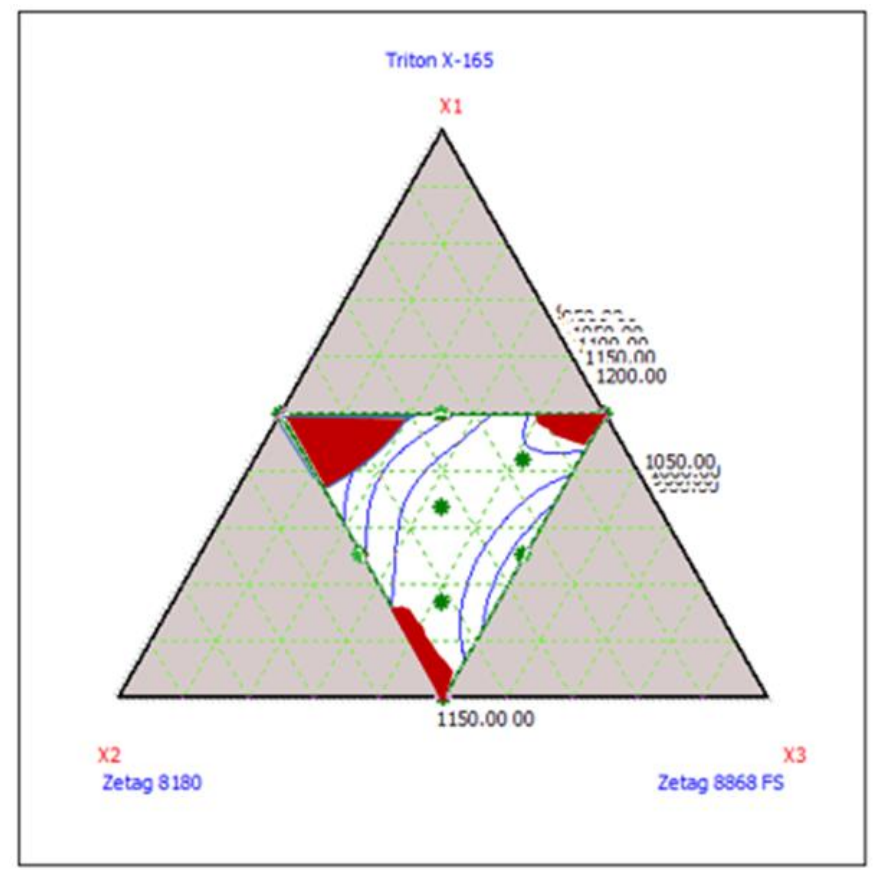

Figure 9. Response surface of the current formulation 
The analysis of the results in Table 7, shows that the average value of the three tests was closer to the estimated response. In the end, we can conclude that the assumed model is statistically validated and can be safely used to predict the response across the experimental area of interest.

Table 7. Predictive and experimental response of the confirmation test

\begin{tabular}{|c|c|c|c|}
\hline Variables & Values & Yexperimental & Y \\
\hline X1 & 0,4 & & \\
\hline X2 & 0,4 & $\mathbf{9 6 4} \boldsymbol{\mu m}$ & $\mathbf{9 7 9 . 8} \boldsymbol{\mu m}$ \\
\hline $\mathbf{X 3}$ & 0,2 & & \\
\hline
\end{tabular}

\section{Conclusion}

In this paper, a mixture design methodology has been successfully applied to prepare a TSP fertilizer enriched by finely and homogeneously dispersed elemental sulfur. Furthermore, from three components, several optimal mixture compositions that lead to particle sizes of elemental sulfur in TSP fertilizer and that meet our aims have been determined $(950 \leq$ size $\leq 1100 \mu \mathrm{m})$.

First of all, several commercial surfactants are used to evaluate their effect on the elemental sulfur dispersion in the TSP fertilizer. By using a screening mixture design methodology, three components have been chosen for the next step of this work. Secondly, due to the use of the mixture design, we were able to postulate and validate a specific cubic model. In the end, the effect of a new formulation composed of three additives was tested and achieved the required particle sizes of elemental sulfur. Indeed, other formulations could be generated using the same experimental procedure proposed to achieve different sulfur particles size.

\section{Acknowledgments}

This work was supported by the research and development initiative of the OCP GROUP. Call for projects about phosphate (APPOS)-sponsored by OCP (OCP Foundation, R\&D OCP, Mohammed VI Polytechnic University, National Center of Scientific and Technical Research CNRST, Ministry of Higher Education, Scientific Research and Professional Training of Morocco MESRSFC). The project entitled: Development of OCP additives for improving the physical quality of fertilizers, project ID *VAL-ELS-01/2017*.

We would like to thank all the staff members of the fertilizers research department of Jorf lasfar (industrial site of OCP GROUP).

\section{References}

1- A. R. Lucheta, M. R. Lambais, Revisão de literatura-Sulfur in Agriculture, R Bras Ci Solo, 2012, 36, 1369-1379.

2- R. C. Silva, M. J. Mclaughlin, Effect of cogranulation on oxidation of elemental sulfur: a theoretical model and experimental validation, Soil Sci Soc Am J. 2016, 80, 1244-1253.
3- J. R. Freney, Oxidation of sulfur in soils, Miner Depos. 1967, 2, 181-187.

4- Y. M. Nor, M. A. Tabatabai, Oxidation of elemental sulfur in soils, Soil Sci Soc Am J. 1977, 41, 736-741.

5- H. H. Janzen, J. R. Bettany, Measurement of sulfur oxidation in soils, Soil Sci. 1987, 143, 444-452.

6- M. Wainwright, Sulfur oxidation in soils, Adv Agron. 1984, 37, 349-396.

7- E. D. Solberg, S. S. Malhi, M. Nyborg, K. S. Gill, B. Henriquez, Source, application method, and cultivation effects on recovery of elemental sulfur as sulfate-S in incubated soils, Commun Soil Sci Plant Anal. 2005, 36, 847-862.

8- K. G. Vogler, W. W. Umbreit, The necessity for direct contact in sulfur oxidation by thiobacillus thiooxidans, Soil Sci. 1941, 51, 331-338.

9- J. J. Germida, H. H. Janzen, Factors affecting the oxidation of elemental sulfur in soils, Fertil Research, 1993, 35, 101-114.

10-S. H. Chien, L. A. Teixeira, H. Cantarella, G. W. Rehm, C. A. Grant, M. M. Gearhart, Agronomic effectiveness of granular nitrogen/phosphorus fertilizers containing elemental sulfur with and without ammonium sulfate: a review, Agron J, 2016, 108, 1203-1213.

11-M. Liebscher, A. Lange, C. Schrofl, R. Fuge, V. Mechtcherine, J. Plank, A. Leonhardt, Impact of the molecular architecture of polycarboxylate superplasticizers on the dispersion of multiwalled carbon nanotubes in the aqueous phase, $\mathbf{J}$ Mater Sci. 2016, 52, 2296-2307.

12-L. Jiang, L. Gao, J. Sun, Production of aqueous colloidal dispersions of carbon nanotubes, $\mathbf{J}$ Colloid Interface Sci. 2003, 260, 89-94.

13-R. M. Fernandes, M. Buzaglo, M. Shtein, I. P. Bar, O. Regev, E. F. Marques, I. Furo, Lateral diffusion of dispersing molecules on nanotubes as probed by NMR, J Phys Chem. 2014, 118, 582-589.

14-H. Ju, Y. Jiang, T. Geng, Y. Wang, A green and easy synthesis method of catanionic surfactant ammonium benzenesulfonate and its surface properties and aggregation behaviors, J Mol Liq. 2018, 264, 306-313.

15-A. Ali, M. Rashid, A. Low, N. Ekmi, A review on recent developments in the adsorption of surfactants from wastewater, J Environ Manage. 
2020, 254, 109797.

16-M. Mishra, P. Muthuprasanna, K. Surya prabha, P. Sobhita rani, I. A. Satish babu, I. Sarath Chandiran, G. Arunachalam, S. Shalini, Basics and potential applications of surfactants-a review, Int J PharmTech Res. 2009, 1, 1354-1365.

17-I. Kurnia, G. Zhang, X. Han, J. Yu, Zwitterionicanionic surfactant mixture for chemical enhanced oil recovery without alkali, Fuel, 2020, 259, 116236.

18-S. Rostamnia, Z. Karimi, M. Ghavidel, Cetyltrimethylammonium bromide- surfactant aqueous micelles as a green and ultra-rapid reactor for synthesis of 5-oxo-2-thioxo-2,5dihydro-3- thiophene carboxylate derivatives, J Sulfur Chem. 2012, 33, 313-318.

19-A. Ayari, H. Mekni, N. Grayaa Jaoued, A. Hedhli, Perfluoroalkyl Epoxides: Synthesis and Conversion into Ionic Surfactants, Mediterr. J. Chem. 2012, 2, 374-381.

20-M. O. Iwunze, Interaction of curcumin with berberine hydrochloride in Nanoemulsion, Mediterr J Chem. 2018, 6, 68-74.

21-C. P. Allais, K. J. Hutter, R. A. G. Martinez, Process for preparing an emulsion of elemental sulfur particles, Patent $N^{\circ}$ 9,598,322,21, 2017.

22-L. E. Ott, Aqueous sulfur dispersion having reduced corrosive activity toward ferrous metal, Patent $\mathrm{N}^{\circ}$ 4,321, 079, 1982.

23-P. Eric, Dispersible sulfur fertilizer pellets, Patent $\mathrm{N}^{\circ}$ WO 2010/118532 A1, 2010.

24-P. Zygmunt, T. Henryk, K. Boguslaw, Sulfur fertilizer and granulated sulfur fertilizer manufacturing method, Patent $\mathrm{N}^{\circ} \mathrm{WO}$ 2008/024007 A2, 2008.

25-J. B. M. Antens, R. A. Garcia Martinez, R. Lambert, J. T. O'brien, M. J. Reynhout, G. M. M. Verbist, Sulfur-containing fertilizers and process for the preparation thereof, Patent $\mathrm{N}^{\circ}$ WO 2010/086395, 2010.

26-J. A. Cornell, Experiments with mixtures: designs, models, and the analysis of mixture data, Third Edition, Wiley series, New York, 2002, 1-649.

27-H. Scheffe, The simplex-centroid design for experiments with mixtures, J R Stat Soc, 1963, 25, 235-263.

28-M. A. Bezerra, V. A. Lemos, C. G. Novaes, R. M. de Jesus, H. R. S. Filho, S. A. Araújo, Application of mixture design in analytical chemistry, Microchem J, 2020, 152, 104336.

29-J. Jacyna, M. Kordalewska, M. J. Markuszewski, Design of experiments in metabolomics-related studies: An overview, J Pharm Biomed Anal, 2019, 164, 598-606.

30-B. Y. Gajera, D. A. Shah, R. H. Dave, Development of an amorphous nanosuspension by sono-precipitation-formulation and process optimization using design of experiment methodology, Int J Pharm. 2019, 559, 348-359.

31-M. V. Mancenido, R. Pan, D. C. Montgomery, C. M. Anderson-cook, Comparing D-optimal designs with common mixture experimental designs for logistic regression, Chemom Intell Lab Syst. 2019, 187, 11-18.

32-M. Claeys-Bruno, C. Gomes, C. Bruno, M. Sergent, Comparative study of mixture designs for complex phenomena, Chemom Intell Lab Syst. 2018, 178, 65-72.

33-M. L. G. Zambrozi, F. T. De Oliveira, P. S. Kaori, R. B. Edward, I. S. Spacino, Statistical mixture design- Principal component determination of synergic solvent interactions for natural product extractions, Chemom Intell Lab Syst. 2010, 103, 1-7.

34-K. R. Quinlan, D. K. J. Lin, Run order considerations for Plackett and Burman Designs, J Stat Plan Inference, 2015, 165, 56-62.

35-S. Marouane, N. Oumam, A. Abourriche, A. Bennamara, M. Charrouf, Optimization of activated carbon from residues of oregano using experimental design method, Mediterr J Chem. 2012, 1, 210-220.

36-B. El Hilal, A. El Harfi, Radioactive wastes Conditioning. Optimization of operating parameters by experience plan method, Mediterr. J. Chem. 2016, 5, 367-373.

37-R. D. Snee, D. Marquardt, Screening concepts and designs for experiments with mixtures, Technometrics, 1976, 18, 19-29.

38-F. Rispoli, V. Shah, A new efficient mixture screening design for optimization of media, Biotechnol Prog. 2009, 25, 980-985.

39-R. P. Niedz, T. J. Evens, Mixture screening and mixture-amount designs to determine plant growth regulator effects on shoot regeneration from grapefruit (Citrus paradisi macf.) epicotyls, Vitr Cell Dev Biol - Plant, 2011, 47, 682-694.

40-L. Chen, Z. Zhang, W. Gong, Z. Liang, Quantifying the effects of fuel compositions on GDI-derived particle emissions using the optimal mixture design of experiments, Fuel, 2015, 154, 252-260.

41-M. Coronado, A. M. Segadães, A. Andrés, Using mixture design of experiments to assess the environmental impact of clay-based structural ceramics containing foundry wastes, J Hazard Mater. 2015, 299, 529-539.

42-A. Hakam, M. Khouloud, Y. Zeroual, Manufacturing of superphosphates SSP \& TSP from downstream phosphates, Procedia Eng. 2012, 46, 154-158.

43-A. Fourati, A. Amor, S. Hédi, M. Zid, N. Ammar, M. Loungou, A. Chouaya, M. J. Ncid, Process for producing triple superphosphate (TSP) and complex fertilizers which are granulated, with reaction devices, for granulation-drying, for packaging the product and for treating the waste, Patent $N^{\circ}$ WO2016043673A1, 2016.

44-N. Chaouqi, M. El Gharous, M. Bouzziri, The improvement of TSP fertilizer production \& Quality, bioRxiv, 2017.

45-C. P. Allais, K. J. Hutter, R. A. Garcia Martinez, Process for preparing an emulsion of elemental 
sulfur particles, Patent $\mathrm{N}^{\circ}$ WO 2014/009326 A1, 2014.

46-M. J. B. Antens, R. A. Garcia Martinez, R. Lambert, J. T. O'brien, M. J. Reynhout, G. L. M. Verbist, Sulfur-Containing fertilizers and process for the preparation thereof, Patent $\mathrm{N}^{\circ}$ WO2010086396A1, 2010.

47-B. Dimitrios, Method for coating fertilizer beads with elemental sulfur, Patent $\mathrm{N}^{\circ}$ WO 2017/077350 A1, 2017.

48-K. J. Hutter, R. A. Garcia Martinez, Process for preparing an elemental sulfur-containing fertilizer, Patent $\mathrm{N}^{\circ} 2429975$ B1, 2010.

49-K. J. Hutter, I. C. James, R. A. Garcia Martinez, Process for the manufacture of sulfur-containing compositions and sulfur-containing fertilizer compositions, Patent $N^{\circ}$ WO 2013/098404 A1, 2013.

50-S. F. Valle, A. S. Giroto, R. Klaic, G. G. F. Guimar, Sulfur fertilizer based on inverse vulcanization process with soybean oil, Polym Degrad Stab. 2019, 162, 102-105.

51-R. D. B. Lefroy, Sholeh, G. Blair, Influence of sulfur and phosphorus placement, and sulfur particle size on elemental sulfur oxidation and the growth response of maize (Zea mays), Aust J Agric Res. 1997, 48, 485-495.
52-D. Dhiba, J. Maghnouj, D. Msatef, Procedé de fabrication d'engrais granulés à base de triple superphosphate enrichis en soufre, Patent $\mathrm{N}^{\circ} \mathrm{MA}$ 25107NA, 2000.

53-M. A. Bezerra, V. A. Lemos, C. G. Novaes, R. M. de Jesus, H. R. S. Filho, S. A. Araujo, J. P. S. Alves, Application of mixture design in analytical chemistry, Microchemical J. 2020, $152,104336$.

54-M. A. Bezerra, R. E. Santelli, E. P. Oliveira, L. S. Villar, L. A. Escaleira, Response surface methodology (RSM) as a tool for optimization in analytical chemistry, Talanta, 2008, 76, 965-977.

55-L. J. Saunders, R. A. Russell, D. P. Crabb, The Coefficient of Determination: What determines a useful $\mathrm{R}^{2}$ Statistic?, Letters, 2012, 53, 6830-6832.

56-C. G. Novaes, R. T. Yamaki, V. F. de Paula, B. B. do Nascimento Junior, J. A. Barreto, G. S. Valasques, M. A. Bezerra, Otimização de métodos analíticos usando metodologia de superfícies de respostas - Parte II : Variáveis de mistura, Rev Virtual Quim. 2018, 10, 393-420.

57-G. Mazerolles, D. Mathieu, R. Phan-Tan-Luu, A. M. Siouffi, Computer-Assisted optimization with Nemrod software, J Chromatogr. 1989, 485, 433-451. 